\title{
Response-specific progestin resistance in a newly characterized Ishikawa human endometrial cancer subcell line resulting from long-term exposure to medroxyprogesterone acetate
}

\author{
SHUJUN ZHAO, GENXIA LI, LI YANG, LEI LI and HONGYU LI \\ Department of Obstetrics and Gynecology, The Third Affiliated Hospital of Zhengzhou University, \\ Zhengzhou 450052, P.R. China
}

Received June 24, 2012; Accepted September 19, 2012

DOI: $10.3892 / \mathrm{ol} .2012 .975$

\begin{abstract}
Progestins, particularly medroxyprogesterone acetate (MPA), have for a long time been used as conservative treatment for young patients with clinical stage I, grade I endometrial carcinoma. However, more than $30 \%$ of patients with endometrial adenocarcinoma display resistance to endocrine therapies at the time of presentation and most cancer patients that initially respond to progestin treatment will at some point develop resistance, resulting in tumor progression. The cellular mechanisms underlying acquired resistance to progestin are poorly understood. In order to investigate the molecular mechanisms whereby human endometrial adenocarcinoma develops resistance to progestin therapy, we have undertaken to develop human endometrial adenocarcinoma cell lines that are resistant to the growth-inhibitory effects of progestins in vitro. A progestin-resistant subcell line of Ishikawa cells was developed from Ishikawa human endometrial adenocarcinoma cells by stepwise selection in increasing concentrations of the synthetic progestin, MPA, over ten months. The doubling time of the progestin-resistant cells $(34.18 \pm 3.15 \mathrm{~h})$ grown routinely in the medium containing $10 \mu \mathrm{M}$ MPA was not significantly different from the doubling time of the parent Ishikawa cells $(35.14 \pm 2.68 \mathrm{~h})$ grown in the absence of MPA ( $\mathrm{t}=-0.331, \mathrm{P}=0.762)$. Moreover, the effect of treatment with MPA shifted from suppression of growth and invasiveness, as observed in the parent Ishikawa cells, to stimulation of growth and invasiveness in the progestin-resistant Ishikawa cells. The positive rates of estrogen receptor a $(\mathrm{ER} \alpha)$ and progesterone receptor $\mathrm{B}$ (PRB) of the progestin-resistant Ishikawa cells were significantly reduced, whilst the positive
\end{abstract}

Correspondence to: Dr Shujun Zhao, Department of Obstetrics and Gynecology, The Third Affiliated Hospital of Zhengzhou University, 7 Kangfu Road, Zhengzhou 450052, P.R. China E-mail: sjzh222@sohu.com

Key words: endometrial carcinoma, resistance to progestin, medroxyprogesterone acetate, estrogen receptor, progesterone receptor rate of ER $\beta$ was significantly enhanced compared to the parent Ishikawa cells. These differences were statistically significant $(\mathrm{P}<0.05)$. Our results indicate that long-term treatment with MPA in Ishikawa cells may give rise to a resistance effect to MPA. When the resistant subtype is acquired, treatment with MPA enhances cancer cell proliferation and invasiveness. The imbalance of ER and PR subtypes may contribute to the mechanisms involved in progestin resistance. Determination of the subtypes of ER and PR may provide important additional information on the hormone sensitivity of endometrial carcinoma.

\section{Introduction}

Endometrial carcinoma is commonly believed to have a relatively good prognosis. Hysterectomy with bilateral oophorectomy usually leads to complete remission and long-term survival, although surgery deprives these patients of fertility potential $(1,2)$. However, approximately $2-14 \%$ of patients who suffer from endometrial carcinoma are below aged 40 . The younger patients are frequently nulligravid with a history of infertility and a strong desire to preserve fertility (1-5). Therefore, a more conservative medical treatment is desirable in young patients who wish to preserve their fertility. Progestins, particularly medroxyprogesterone acetate (MPA), have long been used as a conservative treatment for young patients with clinical stage I, grade I endometrial carcinoma. The response rate varies from $57-75 \%$ (1-3). It has been reported that conservative treatment followed by IVF enables such patients to achieve a successful pregnancy. These relatively good response rates are encouraging with respect to the possibility of conservative treatment by progestins in young patients (1-5). However, more than $30 \%$ of patients with endometrial adenocarcinoma displayed resistance to endocrine therapies at time of presentation. Additionally, most cancer patients that initially respond to progestin treatment will at some point develop resistance, resulting in tumor progression (2). Progestin therapy is limited by the development of resistance in the tumor. The cellular mechanisms underlying acquired resistance to progestin are poorly understood. In order to investigate the molecular mechanisms whereby human endometrial adenocarcinoma develops resistance to 
progestin therapy, we have undertaken to develop human endometrial adenocarcinoma cell lines that are resistant to the growth-inhibitory effects of progestins in vitro. Continuous culture of breast cancer cell lines in the presence of antiestrogen has led to the development of a number of resistant subcell lines (6-8). These represent potentially important models for study of the loss of endocrine sensitivity and the acquisition of the resistant phenotype. In this study, we developed endometrial carcinoma progestin-resistant subcell lines by similar methods. The data presented in this study describe the characteristics of a progestin-resistant subcell line developed from Ishikawa human endometrial adenocarcinoma cells by stepwise selection in increasing concentrations of the synthetic progestin, MPA. The study was approved by the ethics committee of Zhengzhou university, Zhengzhou, China.

\section{Materials and methods}

Routine cell culture and establishment of progestin-resistant cell line. Ishikawa human endometrial carcinoma cells were maintained in our laboratory. These were obtained from an endometrial adenocarcinoma of a 39-year-old woman in 1985 by Nishida, and established as ER- and PR-positive. The cells were routinely cultured in DMEM/F12 medium (Gibco Life Technologies, Carlsbad, CA, USA) supplemented with 5\% fetal bovine serum (Gibco Life Technologies) at $37^{\circ} \mathrm{C}$ in a humidified atmosphere of $5 \% \mathrm{CO}_{2}$. Expressions of ER and PR in parent Ishikawa cells were confirmed by immunocytochemistry. To generate progestin-resistant subcell lines of Ishikawa cells, cells were maintained in the above media supplemented with MPA (Sigma, St. Louis, MA, USA) with $2.5 \mu \mathrm{M}$ increases in MPA concentration (1.0-10 $\mu \mathrm{M})$ every 4 weeks. When the surviving cells had grown to a high density but were still less than confluent, cells were subcultured using $0.02 \%$ EDTA and $0.25 \%$ trysine prepared in Hanks' balanced salt solution. 1/50 of total cells were passaged. Medium containing MPA was replenished every 2-3 days. At each dosage level, several aliquots of cells were frozen and stored in liquid nitrogen. Cells proliferating in $10 \mu \mathrm{M}$ MPA with the same doubling time as the parent Ishikawa cells proliferating in the medium without MPA, were designated progestin-resistant Ishikawa cells (6).The cells were thereafter maintained in $10 \mu \mathrm{M}$ MPA. All treatment stocks were initially prepared in DMSO (vehicle) with subsequent dilution for experiments of more than 1:1000 (for $10^{-5} \mathrm{M}$ ). The presence of a vehicle at such dilutions has previously been shown to have no effect on cell growth.

MTT assay. In some studies, cell number was determined by a MTT assay. MTT (thiazolyl blue) is converted from a yellow-colored salt to a purple-colored formazan by cleavage of the tetrazolium ring by mitochondrial dehydrogenases, the activity of which is linear with cell number. Cells were plated in a 96-well flat-bottomed microplate in $100 \mu \mathrm{l}$ culture medium per well at a cell density of $1-2 \times 10^{4}$ cells $/ \mathrm{ml}$. After treatment as indicated, $10 \mu \mathrm{l}$ MTT (5 mg/ml in PBS) solution was added to each well. After incubation for $4 \mathrm{~h}$, the medium was poured off, and formazan crystals were dissolved with $150 \mu \mathrm{l}$ DMSO by shaking. The absorbance was measured at $490 \mathrm{~nm}$ with a microplate reader. Eight wells were used for each treatment and experiments were repeated at least three times.

Flow cytometry. The parent Ishikawa cells and the progestin-resistant Ishikawa cells were plated at a density of $1.5 \times 10^{6}$ per $6-\mathrm{cm}$-diameter dish (Corning, Inc., Corning, NY, USA) and allowed to grow for $24 \mathrm{~h}$. Subsequently, the medium was changed to serum-free medium and $16 \mathrm{~h}$ later, the cells were incubated with experimental medium. The hormone control group received DMSO (vehicle) alone, whereas the hormone treatment group received $1 \mu \mathrm{M}$ MPA daily. Each experiment was performed in triplicate. Cells were harvested 1, 2, 3 and 4 days after treatment by trypsinization, washed twice with PBS and pelleted by centrifugation for $5 \mathrm{~min}$ at $500 \times \mathrm{g}$. Following this, they were resuspended in PBS and fixed with $75 \%$ cold ethanol. Cells were then resuspended in $1 \mathrm{ml}$ of PI (Sigma) solution containing propidium iodide $50 \mu \mathrm{g}$, and 100 units RNase. Cells were analyzed in a flow cytometer (BD Biosciences, Franklin Lakes, NJ, USA). DNA histograms were prepared using the ModFit analysis program (BD Biosciences), which provides fits for the G0/G1, S and G2/M fractions of the population. The S- and G2/M-phase fractions were combined into a single growth fraction, the proliferative index.

Matrigel invasion assays. The invasion assay of tumor cells was performed using a Transwell cell culture chamber (Corning Costar No. 3422; Corning, Inc.). Prior to the invasion experiments, cells were cultured in serum-free medium containing $1 \mu \mathrm{M}$ MPA or DMSO (vehicle) for $72 \mathrm{~h}$. Polycarbonate filters $(10 \mathrm{~mm})$ were coated on the upper surface with Matrigel (10 mg/200 ml; BD Biosciences, San Jose ,CA, USA). After the filters were dried at room temperature, they were washed gently with phosphate-buffered saline (PBS). Cells were harvested with $0.25 \%$ trypsin, washed and resuspended in serum-free DMEM/F12. The upper compartment of the Matrigel invasion chamber was loaded with $2 \times 10^{5}$ cells, and the lower compartment was filled with $600 \mu 11 \%$ FBS in DMEM/F12 to act as an attractant. The plate was incubated at $37^{\circ} \mathrm{C}$ for $24 \mathrm{~h}$. The cells on the upper side of the filters were gently wiped off; the filters were fixed in methanol and stained with hematoxylin and eosin. The cells that had migrated to the lower side of the filters were counted under a light microscope. The numbers of cells in five defined, high-power fields (magnification, x200) were counted and the average was determined.

Immunocytochemical analysis. The parent Ishikawa cells and the progestin-resistant Ishikawa cells were trypsinized, washed twice with PBS and resuspended in $200 \mu 1$ PBS. Subsequently, $5 \mu \mathrm{l}$ cell suspension was smeared on the slides, dried in air, then fixed by incubation at room temperature for $30 \mathrm{~min}$ with $3.7 \%$ formaldehyde-phosphate-buffered saline and then washed twice with PBS. The cell slides were then immunocytochemically stained, as follows, and endogenous peroxidase activity was blocked by using 3\% hydrogen peroxide. The slides were microwaved in $10 \mathrm{mM}$ citrate buffer ( $\mathrm{pH}$ 6.0) to unmask the epitopes. After incubation with blocking solution for $15 \mathrm{~min}$ at room temperature, the slides were incubated overnight at $4^{\circ} \mathrm{C}$ with monoclonal antibody against ER $\alpha$ (1:100; Santa Cruz Biotechnology, Inc., Santa Cruz, CA, USA), ER $\beta$ (1:200; 
Upstate Biotechnology, Inc., Lake Placid, NY, USA), PR (1:100; Neomarker, Inc., Fremont, CA, USA) and PRB (1:100; Neomarker). Following two 5-min PBS washes, the slides were incubated with biotin-labeled secondary antibody for 30 min. Then, after two 5-min PBS washes, ABC solution (a streptavidin-biotin horseradish complex) was added for $15 \mathrm{~min}$ followed by two PBS washes. The slides were then stained by exposure for 2 min to diaminobenzidine and $0.04 \% \mathrm{H}_{2} \mathrm{O}_{2}$. They were then counterstained with hematoxylin, dehydrated and mounted. Breast carcinoma cell line MCF-7 was used as a positive control. Negative controls were made by replacing the primary antibody with mouse serum. Negative controls yielded non-specific membrane staining. Staining indices were determined by two independent observers.

Statistical analysis. All calculations were performed using the SPSS software package 11.0, ANOVA assay and paired t-test. A P-value less than 0.05 was considered to indicate a statistically significant difference.

\section{Results}

Establishment of the progestin-resistant Ishikawa cell and its growth characteristics in MPA. It has been shown that Ishikawa human endometrial cancer cell line is sensitive to the growth-inhibitory effects of MPA in culture. The cells which are resistant to the growth-inhibitory effects of MPA were selected from the parent Ishikawa cells by stepwise selection in increasing concentrations of MPA (from 1-10 $\mu \mathrm{M}$ ). The cells were thereafter (passage 23) routinely maintained with $10 \mu \mathrm{M}$ MPA in their culture medium. Under this regimen, dramatically slowed growth rates were observed for approximately 24 weeks from initial MPA exposure, after which time cell growth rates progressively increased. The progestin-resistant Ishikawa cells were achieved over a period of approximately 10 months. The doubling time of the progestin-resistant Ishikawa cells $(34.18 \pm 3.15 \mathrm{~h})$ grown routinely in the medium containing $10 \mu \mathrm{M}$ MPA, was not significantly different to the doubling time of the parent Ishikawa cells $(35.14 \pm 2.68 \mathrm{~h})$ grown in the absence of MPA ( $\mathrm{t}=-0.331, \mathrm{P}=0.762)$. Fig. 1 shows the comparison of the parent Ishikawa cells and the progestin-resistant Ishikawa cells growth curves in their routine culture medium.

Effects of MPA on the growth of the parent Ishikawa cells and the progestin-resistant Ishikawa cells. MTT assay was used to determine the effects of MPA on the growth of the parent Ishikawa cells and the progestin-resistant Ishikawa cells. Treatment with MPA reduced the growth of the parent Ishikawa cells. The inhibitory effect was dose-dependent $(\mathrm{F}=29.525, \mathrm{P}=0.000)$; the inhibitory effects were 20,28 and $41 \%$, respectively, when $0.1,1$ and $10 \mu \mathrm{M}$ of MPA were added. Notably, we found that the effect of treatment with MPA shifted from growth suppression, as observed in the parent Ishikawa cells, to growth stimulation in the progestin-resistant Ishikawa cells $(\mathrm{F}=36.20, \mathrm{P}=0.00)$. Low concentration of MPA (0.01 and $0.1 \mu \mathrm{M})$ had no significant effect on the growth of the progestin-resistant cells; the stimulatory effects were 21 and $46 \%$ respectively when 1 and $10 \mu \mathrm{M}$ of MPA were added (Fig. 2).

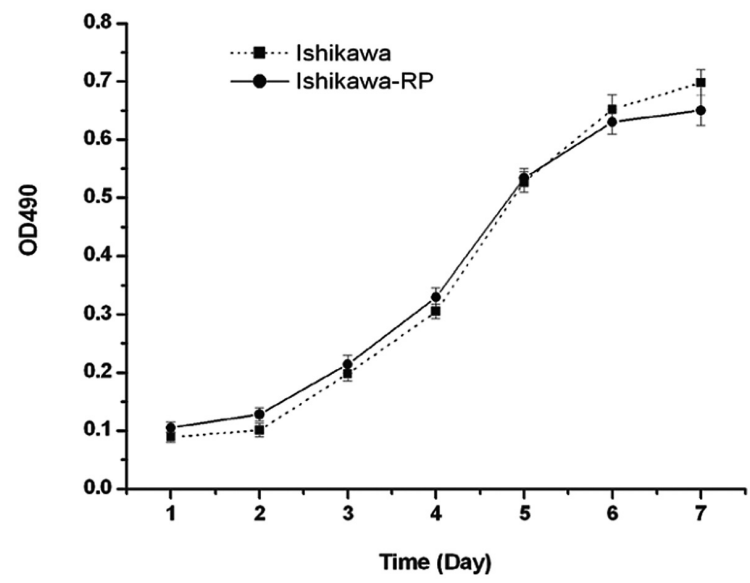

Figure 1. Seven day growth curves of the parent Ishikawa cells and the progestin-resistant Ishikawa cells. MTT assay was used. Cells were plated in 96-well flat-bottomed microplates as described in Materials and methods. The parent Ishikawa cells were grown in the complete medium with absence of MPA. The progestin-resistant Ishikawa cells were routinely maintained in the complete medium containing $10 \mu \mathrm{M}$ MPA. Culture media were changed every other day. Mean doubling times were calculated from the initial (ni) and final (nt) OD490 from the equation: Doubling time $=\log 2 / \log (\mathrm{nt} / \mathrm{ni})$. MPA, medroxyprogesterone acetate.

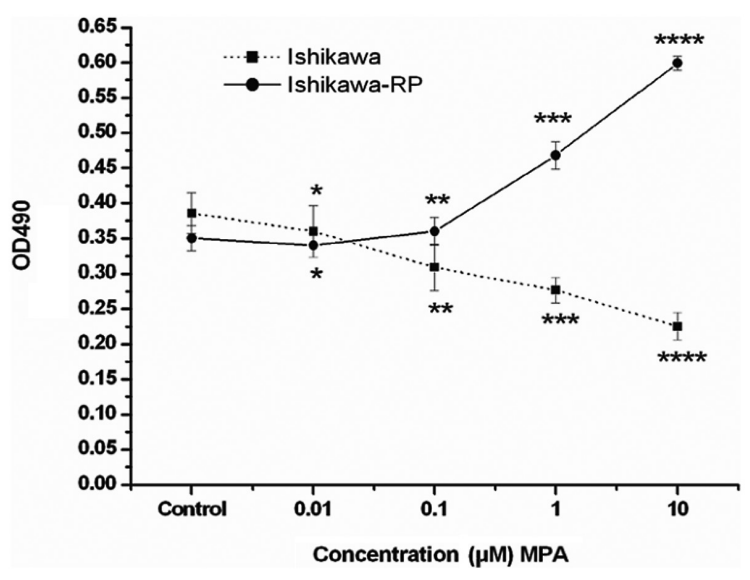

Figure 2. Effects of increasing concentrations of MPA on the proliferation of the parent Ishikawa cells and the progestin-resistant Ishikawa cells. MTT assay was used. Cells were plated in 96-well flat-bottomed plates and allowed to grow for $24 \mathrm{~h}$, then the medium was changed to serum-free medium. After 16-18 $\mathrm{h}$ serum starvation, the cells were incubated with experimental medium containing various concentrations of MPA $(0.01,0.1,1$ and $10 \mu \mathrm{M})$ for $72 \mathrm{~h}$. The control group received DMSO (vehicle) alone. MPA inhibited the parent Ishikawa cell growth. The inhibitory effect was concentration-dependent. ANOVA analysis: $\mathrm{F}=29.525, \mathrm{P}=0.000$, compared with control. ${ }^{*} \mathrm{P}=0.130$, ${ }^{* * *} \mathrm{P}=0.0000,{ }^{* * *} \mathrm{P}=0.0000,{ }^{* * * * *} \mathrm{P}=0.000$. MPA stimulates progestin-resistant Ishikawa cell proliferation, a relatively high concentration of MPA exerts significant stimulatory effect. ANOVA analysis: $\mathrm{F}=30.369, \mathrm{P}=0.000$, compared with control. ${ }^{*} \mathrm{P}=0.188,{ }^{* *} \mathrm{P}=0.333,{ }^{* * *} \mathrm{P}=0.001$ and ${ }^{* * * *} \mathrm{P}=0.000$. Bars, standard error. MPA, medroxyprogesterone acetate.

Effects of MPA on cell cycle distribution in the parent Ishikawa cells and the progestin-resistant Ishikawa cells. Flow cytometry was performed to determine the fraction of cells in the presence of MPA in the parent Ishikawa cells and the progestin-resistant cells. MPA caused time-dependent inhibition of the cell cycle of the parent Ishikawa cells; MPA produced a $14.2 \%$ fall in the proliferation index at day 1 and 
A

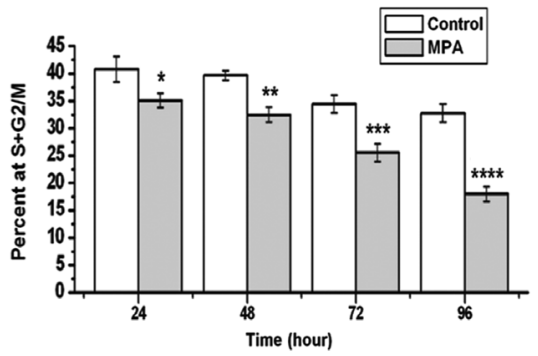

B

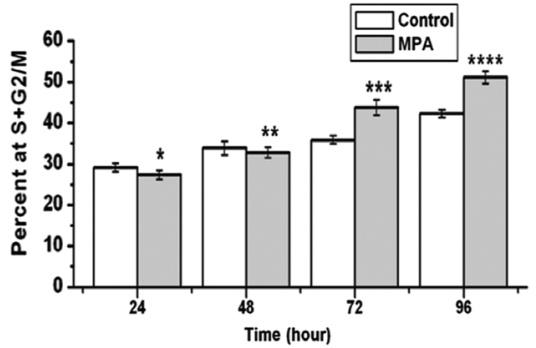

Figure 3. Effects of MPA on the cell cycle of the parent Ishikawa cells and the progestin-resistant Ishikawa cells. DMSO (control) or $1 \mu \mathrm{M}$ MPA was added and the experimental medium refreshed every day. Cells were harvested 1 , 2, 3 and 4 days after treatment. The percentage of cells in S and G2/M was measured by flow cytometry. Bars, standard error. (A) MPA inhibited the parent Ishikawa cell proliferation, compared with control, ${ }^{*}=3.539, \mathrm{P}=0.035$; ${ }^{* *} \mathrm{t}=8.114, \mathrm{P}=0.002 ;{ }^{* * *} \mathrm{t}=4.429, \mathrm{P}=0.011 ;{ }^{* * * *} \mathrm{t}=5.964, \mathrm{P}=0.004$; (B) MPA stimulated the progestin-resistant Ishikawa cell proliferation, compared with control: " $t=2.062, \mathrm{P}=0.108 ;{ }^{* *} \mathrm{t}=1.206, \mathrm{P}=0.344 ;{ }^{* * * *} \mathrm{t}=10.505, \mathrm{P}=0.001$; ***** $t=7.496, \mathrm{P}=0.002$. MPA, medroxyprogesterone acetate.
A

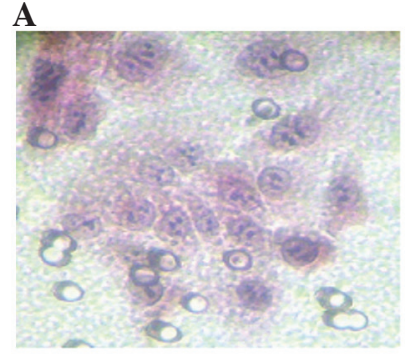

C

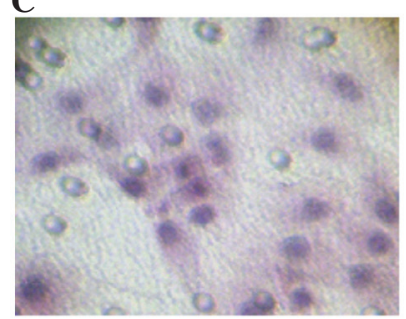

B

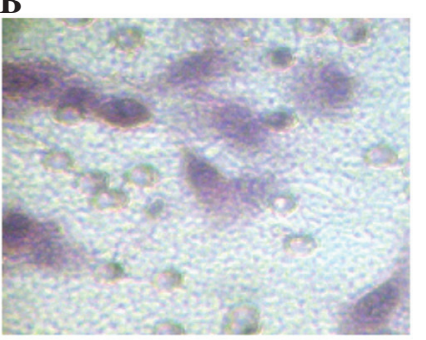

D

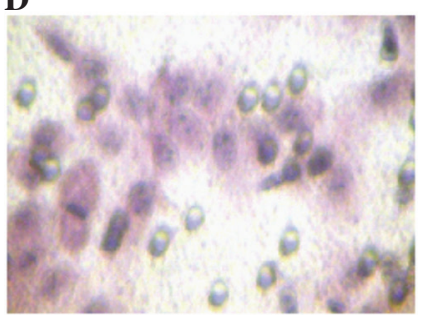

Figure 4. Effects of MPA on the invasive capability of the parent Ishikawa cells and the progestin-resistant Ishikawa cells. Cells were treated with MPA $(1 \mu \mathrm{M})$ or vehicle for $72 \mathrm{~h}$ prior to being harvested and loaded into Matrigel chambers. After incubation, invading cells were stained with HE and photographed at x200 magnification. (A) Parent Ishikawa cells, vehicle control; (B) parent Ishikawa cells, MPA; (C) progestin-resistant Ishikawa cells, vehicle control; (D) progestin-resistant Ishikawa cells, MPA. MPA, medroxyprogesterone acetate.

a $45 \%$ reduction by day 4 (Fig. 3A). In contrast, MPA had no effect on the cell cycle of the progestin-resistant Ishikawa cells on days 1 and 2, but by days 3 and 4, MPA produced an increase in the proliferation index (21.9 and $20.85 \%$, respectively; Fig. 3B).
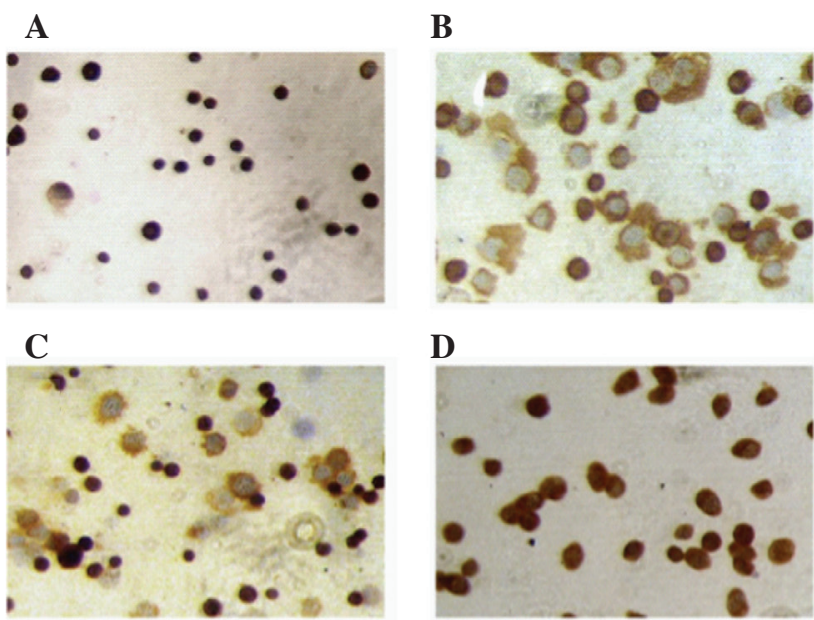

E

$\mathbf{F}$
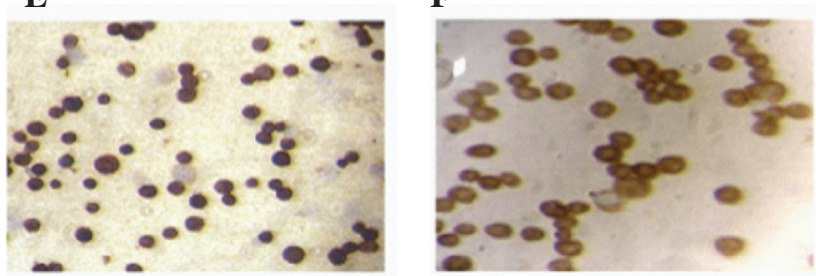

G

H

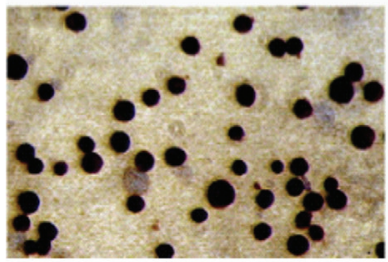

Figure 5. Immunocytohistochemistry of ER $\alpha, \mathrm{ER} \beta, \mathrm{PR}$ and PRB in the parent Ishikawa cells and the progestin-resistant Ishikawa cells. Cells were stained with DAB and photographed at $\mathrm{x} 200$ magnification. (A) ER $\alpha$ expression in the parent Ishikawa cells; (B) ER $\alpha$ expression in the progestin-resistant Ishikawa cells; (C) ER $\beta$ expression in the parent Ishikawa cells. (D) ER $\beta$ expression in the progestin-resistant Ishikawa cells; (E) PR expression in the parent Ishikawa cells; (F) PR expression in the progestin-resistant Ishikawa cells; (G) PRB expression in the parent Ishikawa cells; (H) PRB expression in the progestin-resistant Ishikawa cells. MPA, medroxyprogesterone acetate; ER, estrogen receptor; PR, progesterone receptor.

Effects of MPA on the invasion capability of the parent Ishikawa cells and the progestin-resistant Ishikawa cells. To assess the effects of MPA on cell invasiveness and metastatic potential, cells were seeded on a Matrigel invasion chamber after treatment with MPA or vehicle alone. Cells that successfully invaded through the Matrigel and the pores on the filter were stained with hematoxylin and eosin (Fig. 4) The invasive capability of the progestin-resistant Ishikawa cells was higher than that of the original Ishikawa cells. Notably, a dramatic inhibition of invasiveness caused by MPA treatment in Ishikawa cells $(\mathrm{t}=6.107, \mathrm{P}=0.026)$ and the promotion of invasiveness caused by MPA treatment in progestin-resistant Ishikawa cells $(t=8.660, P=0.013)$ were observed.

Comparison of steroid receptor expression between the parent Ishikawa cells and the progestin-resistant Ishikawa cells. The positive rates of ER $\alpha, \mathrm{PR}$ and PRB were over $95 \%$ and the positive rate of ER $\beta$ was $56 \pm 5 \%$ in the parent Ishikawa cells. 
Compared with parent Ishikawa cells, the positive rates of $\mathrm{ER} \alpha$ and PRB in the progestin-resistant Ishikawa cells were reduced to $28 \pm 3 \%$ and $40 \pm 5 \%$ respectively, and the positive rate of $\operatorname{ER} \beta$ was statistically enhanced to $93.6 \pm 4.5 \%$. These differences were significant $(\mathrm{P}<0.05)$. The positive rate of $\mathrm{PR}$ in the progestin-resistant Ishikawa cells was not different from the parent Ishikawa cells, but the staining intensity was reduced. It could be inferred that downregulation of the B subtype of PR may be due to decreased PR staining intensity. The A subtype of PR was maintained constantly, as shown in Fig. 5.

\section{Discussion}

In human endometrial cancer, the emergence of progesteroneresistant cells reduces the efficacy of progesterone therapy. In order to understand some of the possible mechanisms by which hormonally dependent endometrial cancers develop resistance to progestin therapy, we have developed an endometrial cancer cell line which is resistant to the growth-inhibitory effects of the synthetic progestin, MPA. The progestin-resistant Ishikawa cells, developed from Ishikawa human endometrial cancer cells by stepwise elevation of MPA concentration over a period of 10 months, were grown routinely in the presence of $10 \mu \mathrm{M}$ MPA with a doubling time not significantly different from the parent Ishikawa cell line grown in the absence of progesterone. The parent Ishikawa cells were sensitive to the inhibitory effect of MPA; MPA treatment showed growth suppression in a dose- and time-dependent fashion. This is consistent with previous reports $(1,10)$. In contrast to the parent Ishikawa cells, the progestin-resistant Ishikawa cells were resistant to the growth-inhibitory effects of MPA and inversely, MPA exerted a growth-stimulatory effect. This is in accordance with ' $M$ ' cells, a cell line selected for resistance to the growth-inhibitory effects of MPA from MCF-7 cells, where MPA appears to exert a growth-stimulatory effect (7). It is also concordant with an antiestrogen-resistant cell line selected from an MCF-7 cell line (8). On the other hand, MPA not only exerted a growth stimulatory effect, but also had an invasiveness stimulatory effect on the progestin-resistant Ishikawa cells. It has been reported that some patients who did not respond to progestin treatment presented either invasion of the myometrium and isthmus, lymph node invasion or pelvic metastases, at surgery $(1,5)$. The question of whether these metastases existed before progestin treatment, whether the tumor naturally progressed or whether progestin's stimulatory effects were involved in the process, requires further study.

Progesterone responses are rarely complete in endometrial cancer patients with heterogeneous cancer cells (11). Mechanisms must exist de novo, or evolve during treatment, that allow a proportion of cancer cells to escape progesterone inhibition and ultimately support resistant growth. The progesterone-resistant cells selected from the Ishikawa cell line by stepwise selection may be a combination of primary and acquired drug resistance.

MPA could inhibit Ishikawa cell proliferation and invasiveness, which suggests that using MPA as the conservative treatment method in early-stage endometrial carcinoma is feasible and effective. MPA has been used extensively in the treatment of young patients with endometrial carcinoma as an endocrine therapy with a response rate of approximately $57-75 \%$. Moreover, conservative treatment followed by IVF enables such patients to achieve a successful pregnancy (1-5). Unfortunately, progesterone-resistant cells could arise after long-term treatment with MPA. When progesterone-resistant cell lines arise, MPA treatment could stimulate proliferation and metasis in these progestin-resistant cancer cells. In the period of MPA treatment, we should be cautious of the phenomenon of progesterone resistance.

The presence of the estrogen receptor (ER) and progesterone receptor (PR) are well-known as prerequisites for progestin action $(12,13)$. To date, two ER and PR isoforms have been identified: $\mathrm{ER} \alpha, \mathrm{ER} \beta, \mathrm{PRA}$ and PRB. $\mathrm{ER} \alpha$ and $\mathrm{ER} \beta$ share a high degree of amino acid homology; however, there are significant differences in regions of these receptors that would be expected to influence transcriptional activity. ER $\alpha$ and ER $\beta$ form heterodimers within target cells; ER $\beta$ modulates ER $\alpha$ transcriptional activity; and high levels of ER $\alpha$ significantly inhibit the growth of tumors and downregulate vascular endothelial growth factor expression in tumors xenografted from the Ishikawa cells (14-16). PRB is a 114-KDa protein, whereas PRA is a 94-KDa protein that lacks 164 amino acids from the $\mathrm{N}$-terminus. They are products of a single gene and are translated from individual mRNA species under the control of distinct promoters and have different functions. The magnitude of transcriptional activation of PRB can be significantly greater than that of PRA. It has been reported that progesterone-inhibited cell growth and invasiveness may occur mainly through PRB. Moreover, a drastic decrease of PRB reflects poor prognosis in endometrial cancer patients (17-19). The relative expression level of the ER and PR isoforms may be a key determinant of cellular responses to endocrine treatment. Compared with Ishikawa cells, progestin-resistant Ishikawa cells have decreased the positive expression rate of ER $\alpha$ and PRB, and increased the positive expression rate of ER $\beta$. PRA remained relatively constant over long-term treatment of MPA. Downregulation of ER $\alpha$, PRB and upregulation of ER $\beta$ may be involved in the progestin resistance of endometrial carcinoma. Therefore, it is important to examine ER and PR subsets when evaluating progesterone effects. Abundant PRB, ER $\alpha$ expression in carcinoma cells may be a necessary prerequisite for successful MPA treatment. Progesterone resistance is a complex process; the change in ER and PR did not inhibit the stimulatory effects of MPA on the progestin-resistant cells. A compensatory pathway may therefore exist to support proliferation over long-term MPA treatment (19-25). This requires further study.

From the evidence, it might be concluded that prolonged treatment with MPA in Ishikawa cells could give rise to a resistant effect to MPA. When the resistance subtype is acquired, treatment with MPA is capable of enhancing cancer cell proliferation, invasiveness and metastasis. The imbalance of ER subtype and PR subtype might contribute to the mechanisms involved in the progesterone resistance. Determination of the subtype of ER and PR may provide important additional information on the hormone sensitivity of endometrial carcinoma.

\section{Acknowledgements}

The authors acknowledge the financial support of The Foundation of Technological Innovation of Henan Health (Zhengzhou, China). 


\section{References}

1. Kim JJ and Chapman-Davis E: Role of progesterone in endometrial cancer. Semin Reprod Med 28: 81-90, 2010.

2. Jadoul P and Donnez J: Conservative treatment may be beneficial for young women with atypical endometrial hyperplasia or endometrial adenocarcinoma. Fertil Steril 80: 1315-1324, 2003.

3. Cade TJ, Quinn MA, Rome RM and Neesham D: Progestogen treatment options for early endometrial cancer. BJOG 117: 879-884, 2010

4. Niwa K, Tagami K, Lian Z, Onogi K, Mori H and Tamaya T: Outcome of fertility-preserving treatment in young women with endometrial carcinomas. BJOG 112: 317-320, 2005.

5. Laurelli G, Di Vagno G, Scaffa C, Losito S, Del Giudice M and Greggi S: Conservative treatment of early endometrial cancer: preliminary results of a pilot study. Gynecol Oncol 120: 43-46, 2011.

6. Murphy LC, Dotzlaw H, Wong MS, Miller T and Murphy LJ: Mechanisms involved in the evolution of progestin resistance in human breast cancer cells. Cancer Res 51: 2051-2057, 1991.

7. Coldham NG, Patel K and Braunsberg H: Hormone and cytotoxic drug responsiveness of cultured human breast cancer cells resistant to specific hormones. Int J Cancer 45: 712-718, 1990.

8. Herman ME and Katzenellembogen BS: Response-specific antiestrogen resistance in a newly characterized MCF-7 human breast cancer cell line resulting from long-term exposure to trans-hydroxytamoxifen. J Steroid Biochem Mol Biol 59: 121-134, 1996.

9. Nishida M, Kasahara K, Kaneko M, Iwasaki H and Hayashi K: Establishment of a new human endometrial adenocarcinoma cell line, Ishikawa cells, containing estrogen and progesterone receptors. Nippon Sanka Fujinka Gakkai Zasshi 37: 1103-1111, 1985.

10. Ito K, Utsunomiya $\mathrm{H}$, Yaegashi $\mathrm{N}$ and Sasano $\mathrm{H}$ : Biological roles of estrogen and progesterone in human endometrial carcinoma new developments in potential endocrine therapy for endometrial cancer. Endocr J 54: 667-679, 2007.

11. Zaino RJ, Clarke CL, Mortel R, Satyaswaroop PG and Satyaswaroop PG: Heterogeneity and progesterone-receptor distribution in endometrial adenocarcinoma. Cancer Res 48: $1889-1895,1988$

12. Jongen V, Briët J, de Jong R, ten Hoor K, Boezen M, van der Zee $\mathrm{A}$ and Nijman $\mathrm{H}$ : Expression of estrogen receptor-alpha and -beta and progesterone receptor-A and -B in a large cohort of patients with endometrioid endometrial cancer. Gynecol Oncol 112: 537-542, 2009

13. Stoian SC, Simionescu C, Mărgăritescu C, Stepan A and Nurciu M: Endometrial carcinomas: correlation between ER, PR Ki67 status and histopathological prognostic parameters. Rom J Morphol Embryol 52: 631-636, 2011.

14. Hall JM and McDonnell DP: The estrogen receptor beta-isoform (ERbeta) of the human estrogen receptor modulates ERalpha transcriptional activity and is a key regulator of the cellular response to estrogens and antiestrogens. Endocrinology 140: 5566-5578, 1999.
15. Ali SH, O'Donnell AL, Mohamed S, Mousa S and Dandona P: Overexpression of estrogen receptor-alpha in the endometrial carcinoma cell line Ishikawa: inhibition of growth and angiogenic factors. Gynecol Oncol 95: 637-645, 2004.

16. Ali SH, O'Donnell AL, Balu D, Pohl MB, Seyler MJ, Mohamed S, Mousa S and Dandona P: Estrogen receptor-alpha in the inhibition of cancer growth and angiogenesis. Cancer Res 60: 7094-7098, 2000.

17. Miyamoto T, Watanabe J, Hata H, Jobo T, Kawaguchi M, Hattori M, Saito M and Kuramoto H: Significance of progesterone receptor- $\mathrm{A}$ and $-\mathrm{B}$ expressions in endometrial adenocarcinoma. J Steroid Biochem Mol Biol 2: 110-118, 2004.

18. Smid-Koopman E, Kuhne LC, Hanekamp EE, Gielen SC, De Ruiter PE, Grootegoed JA, Helmerhorst TJ, Burger CW, Brinkmann AO, Huikeshoven FJ and Blok LJ: Progesterone-induced inhibition of growth and differential regulation of gene expression in PRA- and/or PRB-expressing endometrial cancer cell lines. J Soc Gynecol Invest 12: 285-292, 2005.

19. Dai D, Wolf DM, Litman ES, White MJ and Leslie KK: Progesterone inhibits human endometrial cancer cell growth and invasiveness: down-regulation of cellular adhesion molecules through progesterone B receptors. Cancer Res 62: 881-886, 2002.

20. Aghajanova L, Velarde MC and Giudice LC: Altered gene expression profiling in endometrium: evidence for progesterone resistance. Semin Reprod Med 28: 51-58, 2010.

21. Arpino G, Weiss H, Lee AV, Schiff R, De Placido S, Osborne CK and Elledge RM: Estrogen receptor-positive, progesterone receptor-negative breast cancer: association with growth factor receptor expression and tamoxifen resistance. J Natl Cancer Inst 97: 1254-1261, 2005

22. Wang S, Pudney J, Song J, Mor G, Schwartz PE and Zheng W: Mechanisms involved in the evolution of progestin resistance in human endometrial hyperplasia - precursor of endometrial cancer. Gynecol Oncol 88: 108-117, 2003.

23. Yang S, Thiel KW and Leslie KK: Progesterone: the ultimate endometrial tumor suppressor. Trends Endocrinol Metab 22: 145-152, 2011.

24. Engelsen IB, Stefansson IM, Akslen LA and Salvesen HB GATA3 expression in estrogen receptor alpha-negative endometrial carcinomas identifies aggressive tumors with high proliferation and poor patient survival. Am J Obstet Gynecol 199: 543-547, 2008

25. Rubel CA, Jeong JW, Tsai SY, Lydon JP and Demayo FJ: Epithelial-stromal interaction and progesterone receptors in the mouse uterus. Semin Reprod Med 28: 27-35, 2010. 